\title{
THE SPRING ASSESSMENT OF NOSEMA SPP. INFECTION IN HONEY BEE COLONIES (APIS MELLIFERA L.) - SAMPLING AS AN IMPORTANT ASPECT OF A RELIABLE DIAGNOSIS
}

\author{
Krystyna Pohorecka* \\ Andrzej Bober \\ Marta Skubida \\ Dagmara Zdańska \\ National Veterinary Research Institute, Department of Honeybee Diseases, \\ Puławy, Poland \\ *corresponding author: krystyna.pohorecka@piwet.pulawy.pl \\ Received: 11 November 2017; accepted: 17 January 2018
}

\section{Abstract}

The objective of the research was a comparative assessment of the infection levels of Nosema spp. in honey bees collected from different areas of the hive. A total of 588 honey bee colonies were sampled in spring (April-May) 2015 and 2016 through the simultaneous collection of dead worker bees from the bottom board of the hive and live bees from peripheral combs. A microscopic assay of composite samples of 60 bees was used for the detection and quantification of Nosema spp. spores. Consistent positive results of laboratory tests (detection of Nosema spp. spores in both live and dead bee samples) were achieved for $28 \%$ of colonies from surveyed group. In $36 \%$ of colonies both types of samples were Nosema-negative. Spores of Nosema spp. were detected solely in worker bees from the bottom board or exclusively in bees from nests in every $18 \%$ of sampled colonies. No differences were found between the share of colonies that had been identified as Nosema-infected on the basis of an analysis of only the live or dead bees ( $46 \%$ versus $46 \%$ ). Laboratory examination of both types of bee samples can improve the reliability and accuracy of spore counting for the diagnosis of Nosema spp. infection in spring. The introduction of this sampling strategy in routine laboratory diagnostics can be considered as an alternative to the application of more sensitive PCR methods or sampling a higher number of live bees.

Keywords: composite samples, dead and live bees, microscopic examination, Nosema spp.

\section{INTRODUCTION}

Nosema apis (Zander, 1909) and Nosema ceranae (Fries et al., 1996) microsporidia are obligate intracellular parasites of adult honey bee midgut epithelial cells. Nosemosis, caused by either $N$. apis and/or $N$. ceranae, is one of the most widespread diseases, constitutes a serious bee health problem in temperate regions of the world (Klee et al., 2007; Fries, 2010; Pohorecka et al., 2014).

Nosema spp. infection causes pathological changes in the digestive tract as well as impairs digestion and absorption of nutrients which leads to malnutrition and premature death. This detrimental impact on honey bee colonies may lead to lower colony development and produc- tivity, queen replacement, increased winter losses of bees and colony death (Bailey, 1981; Fries, 1993; Forsgren \& Fries, 2010). Seasonal variation in the level of $N$. apis infection (nosemosis), with the peak in the spring, was also observed during the course of $N$. ceranae (Pickard \& El-Shemy, 1989; Gisder et al., 2010; Traver, Williams \& Fell, 2012).

Despite many harmful effects, the honey bee colonies infected with microsporidia from the genus Nosema show no pathognomonic symptoms, particularly when the infection level is low or medium and just developing. Therefore, laboratory tests are required for the detection of nosemosis. The World Organization for Animal Health (OIE, 2017) indicates two methods to make a correct diagnosis: microscop- 
ic examination and polymerase chain reaction (PCR). The qualitative PCR methods detect the Nosema genus, but only enable a diagnosis to be performed (infected versus not infected), especially at low infection levels (Mulholland et al., 2012).

On the other hand, the qualitative or quantitative microscopic procedure is cheaper, easier and commonly used in UE apiculture. The use of samples consisting of at least sixty older worker bees (foragers), taken either from the hive entrance or from peripheral combs, is recommended in this case. The pooled samples obtained in this way, can be used for spore counting in haemocytometer in order to determine average infection level. Bees can also be examined individually in order to assess the infected versus non-infected worker ratio. Some researchers have believed that this is a better way to measure the infection rate (Doull \& Eckert, 1962; Pickard \& El-Shemy, 1989; Higes et al., 2008).

It was also revealed that there was a high, positive correlation between the proportion of infected bees in a sample and the average number of spores in the corresponding pooled bee sample (Fries, Ekbohm, \& Villumstad, 1984; Pohorecka \& Muszyńska, 1996). In routine apicultural practice, bees, which die during overwintering and then are sampled in early spring from the hive bottom boards (winter debris), are sent to certified laboratories for the Nosema infection levels to be assessed. The question arises, however, whether this method is reliable enough. Fries, Ekbohm, \& Villumstad (1984), Topolska \& Hartwig (2005), Gisder et al., (2010) compared the diagnostic suitability of the samples of dead (winter debris) and live (collected straight from the peripheral combs) bees and discovered that results differed considerably. Therefore, we decided to evaluate the spring level of the Nosema spp. infection by examining both dead (bees from winter debris) and live bee (from brood chamber) samples with the use of common routine microscopic method of counting spores. In this experiment the large number of colonies located throughout Poland was monitored for two consecutive years. We expected this approach to help us to optimize the sampling methods and to determine a more reliable spring diagnosis for further apicultural practice.

\section{MATERIAL AND METHODS}

In total, 588 honey bee colonies from 200 apiaries located in the entire territory of Poland, were monitored by veterinarians in the springs of 2015 and 2016. In order to determine the levels of Nosema spp. infection, two samples of worker bees were taken from each monitored colony. At first, the winter debris was collected by beekeepers during the period from March to the end of April and frozen for further investigations. Then, approximately one-hundred alive worker bees were collected from peripheral combs of the same colonies by veterinarians during an inspection. Most visits occurred in April and only a few in early May. During the visit, the inspectors picked up the samples of winter debris stored by beekeepers and provided both types of samples to our laboratory.

After that, sixty worker bees were randomly collected from each sample to investigate the presence of the Nosemaspp. spores. The routine research procedure applied at the National Veterinary Research Institute, Department of Honey Bee Diseases (the National Reference Laboratory) was used as follows. Abdomens of workers belonging to each of the 60-workersamples were dissected, pooled, and macerated in $60 \mathrm{ml}$ of distilled water with the use of a mortar and pestle, creating a suspension. The suspension was filtered through four layers of thin, loosely woven, cotton fabric. Homogenous suspension obtained in this way was transferred (in the amount needed to cover one chamber grid) to a Büerker haemocytometer after thorough shaking. Spores were counted into 144 squares $(0.2 \times 0.2 \mathrm{~mm})$ under the microscope at $x 400$ magnification.

The final result for each sample was expressed as the spore number in $1 \mathrm{ml}$ of the suspension (per bee). A single microscopic preparation was prepared and examined for each alive and dead bee sample. This method has been validated in 
Table 1.

The results of microscopic examination for Nosema spp. infection of alive bees (from nest) and dead bees (from winter debris) collected from the same colonies in spring

\begin{tabular}{|c|c|c|c|c|c|c|c|c|}
\hline \multirow{2}{*}{$\begin{array}{c}\text { Test } \\
\text { results } \\
\text { of } \\
\text { alive } \\
\text { bees }\end{array}$} & \multirow{2}{*}{$\begin{array}{c}\text { Test } \\
\text { results } \\
\text { of } \\
\text { dead } \\
\text { bees }\end{array}$} & \multirow{2}{*}{$\begin{array}{c}\text { Number of } \\
\text { colonies }\end{array}$} & \multicolumn{3}{|c|}{$\begin{array}{l}\text { Spore count in samples of alive } \\
\text { bees from colonies positive for } \\
\text { Nosema spp.(in mln/bee) }\end{array}$} & \multicolumn{3}{|c|}{$\begin{array}{l}\text { Spore count in samples of dead } \\
\text { bees from colonies positive for } \\
\text { Nosema spp. (in mln/bee) }\end{array}$} \\
\hline & & & min.-max. & $\begin{array}{l}\text { mean } \\
\pm S D\end{array}$ & median & min.-max. & $\begin{array}{c}\text { mean } \\
\pm S D\end{array}$ & median \\
\hline+ & + & 162 & $0.3-35.3$ & $4.7 \pm 6.2$ & 2.3 & $0.3-76.9$ & $8.3 \pm 11.2$ & 4.5 \\
\hline+ & - & 106 & $0.3-32.0$ & $3.3 \pm 4.5$ & 1.8 & 0 & 0 & 0 \\
\hline- & + & 106 & 0 & 0 & 0 & $0.4-20.3$ & $3.7 \pm 3.7$ & 2.4 \\
\hline - & - & 214 & 0 & 0 & 0 & 0 & 0 & 0 \\
\hline \multicolumn{2}{|c|}{ Total } & 588 & $0.3-35.3$ & $4.2 \pm 5.6$ & 2.2 & $0.3-76.9$ & $6.5 \pm 9.3$ & 3.7 \\
\hline
\end{tabular}

(-) Nosema-negative - samples without detected spores; (+) Nosema-positive - samples with detected spores.

laboratory conditions - the limit of quantification was set at $3.16 \times 10^{4}$ spores/ml suspension with expanded uncertainty $(U)$ equal to 0.38 in $\log _{10}$ and coefficient of variation (CV) 3.75\% (for low level of infection). The procedure complies with the requirements of the OIE (2017) and conforms with the recommendations of the European Union Reference Laboratory (EU RL) for Honeybee Health (ANSES, France). The comparative laboratory testing (CLT) on Nosema spore counting through microscopic examination organized by the EURL for Honeybee Health in 2017 confirmed our competence in this area (satisfactory specificity - SP and sensitivity - SE).

\section{RESULTS}

Microsporidia from genus Nosema were detected in $46 \%$ samples of alive worker bees and in the same proportion of dead-worker-bee samples. Comparing the results of microscopic examination of both sample types for each colony, we found that the compatible either Nosema-positive or Nosema-negative test results were obtained for samples collected from $28 \%$ and $36 \%$ colonies, respectively (Tab. 1). In $18 \%$ of honey bee colonies the Nosema spp. spores were found only in the winter debris and another $18 \%$ were colonies in which the microsporidia were detected only in the alive-bee samples. Therefore, when considering only one matrix, regardless of its type, the nosemosis was not detected in $18 \%$ of the colonies. The mean spore count per bee varied between alive and dead bees from the colonies with Nosemapositive samples of both types and was twice as high in dead bee samples (Tab. 1). The spore counts from alive worker bees were similar in colonies with both Nosema-positive and Nosema-negative samples of winter debris. The average level of infection with Nosema spp. was twice as low in dead bees from colonies with Nosema-negative worker bees from brood chamber compared to colonies with Nosemapositive samples of this kind.

\section{DISCUSSION}

The prevalence of Nosemaspecies was balanced and amounted to $46 \%$ for both the dead and alive bee samples. The obtained results suggest that both types of diagnostic material may be considered as equally useful for the qualitative microscopic diagnosis of Nosema spores. The actual proportion of Nosema spp. positive colonies was 18\% higher. Assessing these two sample types allowed the detection of $64 \%$ prevalence of Nosema disease. However, in previous studies in which composite samples of 60 or more alive and dead bees had been compared, opposite results were obtained (Fries, Ekbohm, \& Villumstad, 1984; Topolska 
\& Hartwig, 2005). One reason for this might be the significant differences in the number of samples tested in ours and in the remaining experiments.

Fries, Ekbohm, \& Villumstad (1984) examined dead and alive bees in early spring and found Nosema infection in $74 \%$ and $48 \%$ of colonies, respectively. This means that through testing of the winter debris, a significantly higher percentage of colonies infected with Nosema species were detected. However, numerous studies have shown that the examination of bees from winter debris does not give an accurate picture of the Nosema spp. infection level within alive bees originated from the same colony and that there is a lack of a correlation between average spore count per dead bee and average spore count per alive bee taken from the same colony (Fries, Ekbohm, \& Villumstad, 1984; Pohorecka \& Muszyńska, 1996; Higes et al., 2008).

Contrary to the study by Fries, Ekbohm \& Villumstad (1984), the higher accuracy of Nosema diagnostics carried out with alive bees was proven by Topolska \& Hartwig (2005). In their study $85 \%$ colonies were detected to be infected with Nosema spp. when the alive bees were assayed, whereas only $44 \%$ colonies appeared to be infected when the dead bees were examined. Gisder et al. (2010) drew differing conclusions when they examined both alive and dead bees (collected from the bottom boards). These authors detected and differentiated qualitative Nosema and their results did not differ between the dead and alive bee samples taken from the same colony.

The accuracy of nosemosis diagnosis could be influenced by sample size, place, sampling date and time, intra-colony variation in infection levels, and laboratory diagnostic methods (Higes et al., 2008; Meana, Martín-Hernández \& Higes, 2010; Botias et al., 2012; Mulholland et al., 2012; Traver, Williams, \& Fell, 2012). Рагticularly because of polyandry, the expression of several traits greatly varies within a bee colony, which consists of genetically and physiologically different groups of workers (Paleolog, 2009; Borsuk at al., 2011). Studies performed on bumblebees have shown that the antagonistic relationship between Nosema bombi parasites and their hosts is strongly influenced by genotype-by-genotype interactions and that the presence of $N$. bombi in specific host genotypes relates to infection prevalence (Manlik, SchmidHempel, \& Schmid-Hempel, 2017). Therefore, particularly in honeybees, a reliable worker colony-sample should be numerous enough, and joint testing of samples of workers both alive from nests and dead from winter debris should be recommended. Moreover, the comparison of our results with those of Paleolog (2009), Borsuk at al. (2011), and Manlik, Schmid-Hempel \& Schmid-Hempel (2017) suggests that the quantitative assessment of the colony Nosema spp. health-status should be based on samples of nest alive bees, which better reflect the inter-colony worker variability.

In the diagnostic layer, the PCR technique provides higher diagnostic sensitivity by being able to identify the immature Nosema stages (Traver, Williams, \& Fell, 2012; Mulholland et al., 2012). Unfortunately, molecular tools are still rarely used by official laboratories in routine laboratory diagnostics of nosemosis. An increase in the number of bees per sample ensures the quality of the diagnosis, but its application is cumbersome and of very low practical use.

To sum up, simultaneous examination of alive bees taken from nest and dead bees of winter debris can improve the accuracy of the microscopic detection of Nosema spp. in spring, particularly in honeybee colonies with a low level of infection. Such a procedure will be particularly important for monitoring the prevalence of nosemosis (proportion of the sampled colonies found infected). Nevertheless, we believe that the quantitative assessment of the intensity (number of spores per bee) of Nosema spp. infection in alive honey bee colonies should be based on samples of alive bees.

\section{ACKNOWLEDGMENTS}

We appreciate the comments of reviewers whose reviews helped to improve the manuscript. We thank the colleagues from 
Department of Honeybee Diseases, National Veterinary Research Institute for their laboratory assistance.

This study was supported by the Ministry of Agriculture and Rural Development, Multi-Annual Program National Veterinary Research Institute in Pulawy "Animal health and public health protection" 2014-2018.

\section{REFERENCES}

Bailey, L. (1981). Honey Bee Pathology. London, UK: Academic Press.

Botías, C., Martín-Hernández, R., Meana, A., \& Higes, M. (2012). Critical aspects of the Nosema spp. diagnostic sampling in honey bee (Apis mellifera L.) colonies. Parasitology Research, 1106), 2557-2561. https://doi.org/10.1007/s00436-011-2760-2

Borsuk, G., Olszewski, K., Strachecka, A., \& Paleolog, J. (2011). The interaction of worker bees which have increased genotype variance. II. Cage tests of sugar syrup collecting and mortality. Journal of Apicultural Science, 55 (1), 59-65.

Doull, K.M., \& Eckert, J.E. (1962). A survey of the incidence of Nosema disease in California. Journal of Economic Entomology, 55(3), 313-317. https://doi. org/10.1093/jee/55.3.313

Forsgren, E., \& Fries, I. (2010). Comparative virulence of Nosema ceranae and Nosema apis in individual European honey bees. Veterinary Parasitology, 1703-4), 212-217, https://doi.org/10.1016/j. vetpar.2010.02.010

Fries, I. (1993). Nosema apis - a parasite in the honey bee colony. Bee World,74(1), 5-19. http://dx.doi.org/1 0.1080/0005772X.1993.11099149

Fries, I. (2010). Nosema ceranae in European honey bees (Apis mellifera). Journal of Invertebrate Pathology, 103, S73-S79. https://doi.org/10.1016/j. jip.2009.06.017

Fries, l., Ekbohm, G., \& Villumstad, E. (1984). Nosema apis, sampling techniques and honey yield. Journal of
Apicultural Research, 23(2), 102-105. http://dx.doi.or g/10.1080/00218839.1984.11100617

Fries, I., Feng, F., Da Silva, A., Slemenda, S.B., Pieniazek, N.J. (1996). Nosema ceranae n. sp. (Microsроra, Nosematidae), morphological and molecular characterization of a microsporidian parasite of the Asian honey bee Apis cerana (Hymenoptera, Apidae). European Journal of Protistology, 32, 356-365. https://doi.org/10.1016/S0932-4739(96)80059-9

Gisder, S., Hedtke, K., Möckel, N., Frielitz, M.C., Linde, A., Genersch, E. (2010). Five-year cohort study of Nosema spp. in Germany: does climate shape virulence and assertiveness of Nosema ceranae? Applied and Environmental Microbiology, 76(9), 3032-3038. DOl: 10.1128/AEM.03097-09

Higes, M., Martín-Hernández, R., Botías, C., Bailón, E.G., González-Porto, A.V., Barrios, L., .... Meana, A. (2008). How natural infection by Nosema ceranae causes honeybee colony collapse. Environmental Microbiology, 1010), 2659-2669. DOl: 10.1111/j.14622920.2008.01687.x

Klee, J., Besana, A.M., Genersch, E., Gisder, S., Nanetti, A., Tam, D.Q., ... Paxton, R.J. (2007). Widespread dispersal of the microsporidian Nosema ceranae, an emergent pathogen of the western honey bee, Apis mellifera. Journal of Invertebrate Pathology, 96(1), 1-10. https://doi.org/10.1016/j.jip.2007.02.014

Manlik, O., Schmid-Hempel, R., \& Schmid-Hempel P. (2017). Parasite infection of specific host genotypes relates to changes in prevalence in two natural populations of bumblebees. Infection Genetics and Evolution, 56, 125-132. DOl: 10.1016/j. meegid.2017.11.019

Meana, A., Martín-Hernández, R., \& Higes, M. (2010). The reliability of spore counts to diagnose Nosema ceranae infections in honey bees. Journal of Apicultural Research, 49(2), 212-214. http://dx.doi. org/10.3896/IBRA.1.49.2.12

Mulholland, G.E., Traver, B.E., Johnson, N.G., \& Fell R.D. (2012). Individual variability of Nosema ceranae infections in Apis mellifera colonies. Insects, 3(4): 


\section{3-1155. DOl: 10.3390/insects3041143}

Paleolog, J. (2009). Behavioural characteristics of honey bee (Apis mellifera) colonies containing mix of workers of divergent behavioural traits. Animal Science Papers and Reports, $2 \lambda$ 3), 237-248.

Pickard, R.S., \& El-Shemy, A.A.M. (1989). Seasonal variation in the infection of honeybee colonies with Nosema apis Zander. Journal of Apicultural Research, 28(2), 93-100. http://dx.doi.org/10.1080/00218839. 1989.11100828

Pohorecka, K., Bober, A., Skubida, M., Zdańska, D., Torój, K. (2014). A comparative study of environmental conditions, bee management and the epidemiological situation in apiaries varying in the level of colony losses. Journal of Apicultural Science, 58(2): 107-132. https://doi.org/10.2478/jas-2014-0027

Pohorecka, K., \& Muszyńska, J. (1996). Comparison of different methods to measure the infestation level of wintering honeybee colonies by the spores of Nosema apis Z. Pszczelnicze Zeszyty Naukowe, 40, 129-139.

Topolska, G., \& Hartwig, A. (2005). Diagnosis of Nosema apis infection by investigations of two kinds of samples: dead bees and live bees. Journal of Api- cultural Science, 42(2), 75-79.

Traver, B.E., Williams, M.R., \& Fell, R.D. (2012). Comparison of within hive sampling and seasonal activity of Nosema ceranaein honey bee colonies. Journal of Invertebrate Pathology, 109(2):187-193. D0l:10.1016/j. jip.2011.11.001

World Organisation for Animal Health (OIE). (2017). Manual of Diagnostic Tests and Vaccines for Terrestrial Animals, Chapter 2.2.4 Nosemosis of honey bees, 1-6. Available online: http://www.oie.int/fileadmin/Home/eng/Health_standards/tahm/2.02.04_ NOSEMOSIS.pdf.

Zander, E. (1909). Tierische Parasiten als Krankenheitserreger bei der Biene. Münch. Bienen-Zeitung, 37, 196-204. 